\title{
Dietary Supplementation of Citrus limon L. (Lemon) and Evaluation of Its Role to Prevent and Cure of Vitamin C Deficiency Diseases
}

\author{
Zubaer Hosen ${ }^{1, ~ *, ~ S h a h i n ~ A f r o z ~ B i p a s h a ~}{ }^{1}$, Sadat Kamal ${ }^{1}$, Sumaiyah Rafique $^{2}$, Bariul Islam ${ }^{1}$, \\ Kaniz Fatema ${ }^{1}$ \\ ${ }^{1}$ Department of Applied Nutrition and Food Technology, Islamic University, Kushtia, Bangladesh \\ ${ }^{2}$ Department of Food and Nutrition, University of Dhaka, Dhaka, Bangladesh
}

Email address:

zubaeranftiugmail.com (Z. Hosen), bipashaislam34@gmail.com (S. A. Bipasha), sadatkama138@gmail.com (S. Kamal), sumaiyah.rafique@gmail.com (S. Rafique), bariulanftiu@gmail.com (B. Islam), limaazad93@gmail.com (K. Fatema)

${ }^{*}$ Corresponding author

\section{To cite this article:}

Zubaer Hosen, Shahin Afroz Bipasha, Sadat Kamal, Sumaiyah Rafique, Bariul Islam, Kaniz Fatema. Dietary Supplementation of Citrus limon L. (Lemon) and Evaluation of Its Role to Prevent and Cure of Vitamin C Deficiency Diseases. International Journal of Nutrition and Food Sciences. Vol. 9, No. 1, 2020, pp. 1-5. doi: 10.11648/j.ijnfs.20200901.11

Received: December 30, 2019; Accepted: January 9, 2020; Published: February 4, 2020

\begin{abstract}
Vitamin C is an essential dietary component must be ingested for survival. Because of not being produce in the body it must be supplied exogenously by foods and supplements. Citrus limon L. (Lemon) is a citrus fruits, cheap but rich sources of vitamin C. Due to high levels of vitamin C content, it can prevent and cure the vitamin $\mathrm{C}$ related disease including gum bleeding, poor wound healing, skin diseases, tiredness, joint pain and edema. A total of 200 people (105 were males and 95 were females) were selected for the study. In order to assess vitamin C status, symptoms like gum bleeding, poor wound healing, hyperkeratosis, excessive tiredness, joint pain and edema were collected by means of a structured questionnaires. People were then divided into two groups randomly. One group was the focus of the lemon supplementation group and another was the non-supplementation group. Then we supplied lemon to the individuals (2piece/day) of lemon supplementation group for 4 months and no lemon was provided to the non-supplementation group during the study period. After four months, we found that symptoms like gum bleeding (92.5\%), poor wound healing (89.29\%), hyperkeratosis $(50 \%)$, excessive tiredness $(89.83 \%)$, joint pain $(69.23 \%)$ and edema $(30 \%)$ have been cured in lemon supplementation group. On the other hand, after four months gum bleeding, poor wound healing, hyperkeratosis, excessive tiredness, joint pain and edema in nonsupplementation group have not been cured like lemon supplementation group. The percentages were $20 \%, 21.05 \%, 33.33 \%$, $25 \%, 14.81 \%$ and $14.29 \%$ respectively.
\end{abstract}

Keywords: Vitamin C, Scurvy, Lemon, Supplementation, Prevent, Cure

\section{Introduction}

Importance of vitamin $\mathrm{C}$ for human and animal health is unambiguous. It is essential but cannot synthesized endogenously in humans and most other animals [1]. It has different unanimous body functions including biosynthesis of collagen, certain neurotransmitters and protein metabolism $[1,2]$. Additionally, it plays physiological function such as an anti-oxidant and also regenerate other anti-oxidant including vitamin E [3, 4]. Scurvy is well known disease caused by acute vitamin C deficiency [5-7]. Depending on vitamin C stores in body the timeline of the development of scurvy varies, but signs can appear within 1 month of little or no vitamin C intake (below $10 \mathrm{mg} /$ day) [8-10]. Fatigue (probably the result of impaired carnitine biosynthesis), malaise, and inflammation of the gums are the initial symptoms of vitamin $\mathrm{C}$ deficiency diseases [4, 7]. Due to progression of vitamin $\mathrm{C}$ deficiency, collagen synthesis becomes impaired and connective tissues become weakened, causing petechiae, ecchymoses, purpura, joint pain, hyperkeratosis, and corkscrew hairs. Poor wound healing is common in the peoples whose daily diet contain inadequate 
amount of vitamin C [1-6]. Additional signs of scurvy include bleeding gums, depression as well as swollen and loosening or loss of teeth due to tissue and capillary fragility $[6,8,11]$.

Most of the above vitamin $\mathrm{C}$ deficiency diseases are reversible and can be cured by supplementation of vitamin $\mathrm{C}$ rich food. Vitamin $\mathrm{C}$ is mainly found in fruits and vegetables [12]. Citrus limon L. (lemon) is fruit of the citrus group and rich sources of vitamin $C$ [13]. In addition the fiber of citrus fruit also contains bioactive compounds, such as polyphenols, the most important being vitamin $\mathrm{C}$ (or ascorbic acid), and they certainly prevent the cause of scurvy [14]. A medium size lemon $(100 \mathrm{~g})$ contain $53 \mathrm{mg}$ of vitamin $\mathrm{C}$ that met $88 \%$ of recommended dietary allowances (RDAs). The RDAs of vitamin $\mathrm{C}$ for $15-40$ years aged people are $75-90 \mathrm{mg}$ [6]. The report indicate that 2 pieces of lemon can met the RDAs of vitamin $\mathrm{C}$ for the people who are 15-40 years old. The role and sources of vitamin $\mathrm{C}$ is well known. Though feeding trial as a dietary supplementation of lemon to prevent and cure of vitamin $\mathrm{C}$ deficiency diseases has not yet been documented. Therefore, this study has been conducted to aware the common peoples about the cheap but rich sources of vitamin $\mathrm{C}$ and its outstanding role to prevent and cure of vitamin $\mathrm{C}$ deficiency diseases.

\section{Methods}

\subsection{Study Area and Data Collection}

This study was carried out during the period of November, 2018 to February, 2019 at a village named Chor-Amlapara beside kushtia city in western region of Bangladesh. A total of 200 study subjects were selected for our study randomly where 105 were males and 95 were females aged between 15-40 years. During the primary enrollment we found that most of the peoples in that region were suffering from different vitamin $\mathrm{C}$ deficiency diseases according to their dietary history, sign and symptoms. We excluded diabetic, asthmatic and cardiovascular disease related patients who have already diagnosed and who were in under treatment of vitamin $\mathrm{C}$ related diseases before the primary enrollment. The diagnosis of vitamin $\mathrm{C}$ deficiency diseases are clinical one. We diagnosed the patients based on their dietary history of inadequate vitamin $\mathrm{C}$ intake and the various manifestations including gum bleeding, hyperkeratosis and edema. On the other hand, excessive tiredness, joint pain and poor wound healing were diagnosed by the history of their physical conditions and activity in daily life and according to the report [15]. All information's were collected through a structured questionnaires. After the confirmation of the vitamin $\mathrm{C}$ deficiency diseases we divided our study populations into two groups randomly. We supplied 2 lemons (medium size about $150 \mathrm{gm}$ ) per individuals per day to a group as a dietary supplement called lemon supplementation group $(n=90)$ and we did not provide any lemon to another group called non-supplementation group $n=110$ ). Fresh lemons were collected from the Kushtia municipal market, NS road, Kushtia. After 3 days frequency visit till four months, we provide 2 pieces (medium) of lemon per individuals per day and ensured to consume it for their improvement of vitamin $\mathrm{C}$ related diseases. After 4 months we collected the symptoms based data again from two groups and analyzed.

\subsection{Data Analysis}

Statistical analyses were performed using the Statistical Packages for Social Sciences (SPSS version 21.0, SPSS, USA) software. Characteristics of the study participants were analyzed to compare the study subjects of lemon supplementation group and non-supplementation group by independent sample T-test for continuous and $\chi^{2}$ test for categorical variables. All statistical significance tests were two-tailed.

\section{Results}

\subsection{Characteristics of the Study Participants}

Table 1 shows the basic characteristics of the study participants. The average (mean $\pm \mathrm{SD}$ ) age, BMI and the parameters (occupation, education and monthly income) related to socioeconomic condition were almost similar in the lemon supplementation and non-supplementation groups. Most of the female subjects were housewives and most of the males were rickshaw pullers and hawkers. A greater part of the total subjects had no formal education. We did not find any female smokers. All the study participants were nonalcoholic. Vitamin C deficiency symptoms holding study subjects were almost similarly distributed between two groups.

\subsection{Numbers of Patients Before and After Four Months of Supplementation}

The numbers of participants with vitamin $\mathrm{C}$ deficiency symptoms in lemon supplementation and nonsupplementation groups before and after provide lemon are described in Table 2. A remarkable improvement of vitamin $\mathrm{C}$ deficiency symptoms were found in lemon supplementation group compared to the non-supplementation group. Interestingly, we did not found any new vitamin C deficiency diseased participants after four months from lemon supplementation group. This results indicate that lemon can prevent vitamin $\mathrm{C}$ deficiency diseases.

Table 1. Characteristics of the study participants between lemon supplementation and non-supplementation groups.

\begin{tabular}{llll}
\hline Parameters & All & Supplementation group & Non-supplementation group \\
\hline $\begin{array}{l}\text { Study Subjects (n) } \\
\text { Sex (n) }\end{array}$ & 200 & 90 & 110 \\
Male & 105 & 41 & 64 \\
\hline
\end{tabular}




\begin{tabular}{|c|c|c|c|c|}
\hline Parameters & All & Supplementation group & Non-supplementation group & $p$-value \\
\hline Female & 95 & 49 & 46 & \\
\hline Age (years) ${ }^{a}$ & $27.4 \pm 8.39$ & $27.1 \pm 8.35$ & $27.5 \pm 8.47$ & $0.742^{*}$ \\
\hline BMI $\left(\mathrm{kg} / \mathrm{m}^{2}\right)^{\mathrm{a}}$ & $22.1 \pm 3.43$ & $21.9 \pm 3.08$ & $22.1 \pm 3.71$ & $0.749^{*}$ \\
\hline \multicolumn{5}{|l|}{ Occupation $[\mathrm{n},(\%)]$} \\
\hline \multicolumn{5}{|l|}{ Male } \\
\hline Rickshaw pullers & $27(25.7)$ & $11(26.8)$ & $16(25.0)$ & \multirow{6}{*}{$0.479^{\#}$} \\
\hline Hawkers & $12(11.4)$ & $7(17.1)$ & $5(7.80)$ & \\
\hline Shop-kippers & $10(9.50)$ & $4(9.80)$ & $6(9.40)$ & \\
\hline Business & $12(11.4)$ & $6(14.6)$ & $6(9.40)$ & \\
\hline Students & $20(19.0)$ & $5(12.2)$ & $15(23.4)$ & \\
\hline${ }^{+}$Others & $24(22.9)$ & $8(19.5)$ & $16(25.0)$ & \\
\hline \multicolumn{5}{|l|}{ Female } \\
\hline Housewives & $77(81.1)$ & 47 (95.9) & $30(65.2)$ & \multirow[t]{3}{*}{$<0.001^{\#}$} \\
\hline Students & $5(5.30)$ & $2(4.10)$ & $3(6.50)$ & \\
\hline ‡Others & $13(13.7)$ & $0(0.00)$ & $13(28.3)$ & \\
\hline \multicolumn{5}{|l|}{ Education [n, (\%)] } \\
\hline No formal education & $68(34.0)$ & $41(45.6)$ & $27(24.5)$ & \multirow{3}{*}{$<0.01^{\#}$} \\
\hline Primary & $71(35.5)$ & $33(36.7)$ & $38(34.5)$ & \\
\hline Secondary & $54(27.0)$ & $15(16.7)$ & $39(35.5)$ & \\
\hline Higher & $7(3.5)$ & $1(1.10)$ & $6(5.50)$ & \\
\hline Income/month (US\$) ${ }^{a}$ & $25.3 \pm 8.65$ & $25.6 \pm 7.95$ & $25.1 \pm 9.22$ & $0.727^{*}$ \\
\hline \multicolumn{5}{|l|}{ Smoking in male [n, $(\%)]$} \\
\hline Yes & $34(17.0)$ & $17(18.9)$ & $17(15.5)$ & \multirow{2}{*}{$0.324^{\#}$} \\
\hline No & $166(83.0)$ & $73(81.1)$ & $93(84.5)$ & \\
\hline Alcohol intake & - & - & - & - \\
\hline \multicolumn{5}{|l|}{ Symptoms [n, (\%)] } \\
\hline Gum bleeding & $60(30.0)$ & $40(44.4)$ & $20(18.2)$ & $<0.001^{\#}$ \\
\hline Poor wound healing & $47(23.5)$ & $28(31.1)$ & $19(17.3)$ & $<0.05^{\#}$ \\
\hline Hyperkeratosis & $9(4.50)$ & $6(6.70)$ & $3(2.70)$ & $0.160^{\#}$ \\
\hline Excessive tiredness & $99(49.5)$ & $59(65.6)$ & $40(36.4)$ & $<0.001^{\#}$ \\
\hline Joint pain & $66(33.0)$ & $39(43.3)$ & $27(24.5)$ & $<0.01^{\#}$ \\
\hline Edema & $17(8.50)$ & $10(11.1)$ & $7(6.40)$ & $0.173^{\#}$ \\
\hline
\end{tabular}

${ }^{a}$ Data were presented as mean $\pm \mathrm{SD}$. BMI was calculated as body weight $(\mathrm{Kg})$ divided by height squared $\left(\mathrm{m}^{2}\right)$. ${ }^{*} p$ - and ${ }^{\#} p$ - values between lemon supplementation and non-supplementation groups were from the independent sample T-test and $\chi^{2}$ test, respectively. ${ }^{+}$Others included village doctor, security guard, banker, teacher and day labors. $¥$ Others included teacher, village doctor and tailors. $n=$ number of the study subjects.

Table 2. Numbers of participants with vitamin C deficiency symptoms in lemon supplementation and non-supplementation groups before and after provide lemon.

\begin{tabular}{lllll}
\hline Groups & Symptoms & During data collection (n) & After four months (n, \%) & $\boldsymbol{p}$-value \\
\hline & Gum bleeding & 40 & $4(92.5)$ & $<0.001$ \\
& Poor wound healing & 28 & $3(89.3)$ & $<0.001$ \\
Lemon supplementation & Hyperkeratosis & 6 & $3(50.0)$ & $<0.01$ \\
group & Excessive tiredness & 59 & $6(89.8)$ & $<0.001$ \\
& Joint pain & 39 & $12(69.2)$ & 0.001 \\
& Edema & 10 & $7(30.0)$ & 0.056 \\
& Gum bleeding & 20 & $16(20.0)$ & 0.071 \\
Non-supplementation & Poor wound healing & 19 & $15(21.1)$ & 0.073 \\
group & Hyperkeratosis & 3 & $2(33.3)$ & 0.059 \\
& Excessive tiredness & 40 & $30(25.0)$ & 0.062 \\
& Joint pain & 27 & $23(14.8)$ & 0.135 \\
\hline
\end{tabular}

$\mathrm{n}=$ number of the study subjects. $p$-values were from $\chi^{2}$ test.

\section{Discussion}

To address vitamin $\mathrm{C}$ concentrations found in humans, it is necessary to describe ascorbate availability. Humans can obtain ascorbate only exogenously. Humans consume vitamin $\mathrm{C}$ by mouth with subsequent gastrointestinal absorption and distribution or receive it parenterally. Poor vitamin C status is associated with low socioeconomic status in developed countries. [16, 17]. The Low-Income Diet and Nutrition Survey (LIDNS) provides representative data on the diet and nutritional status of low-income/materially deprived UK consumers in $2003-05$ [18] The socioeconomic conditions of almost all the peoples in our study subjects were very poor (Table 1). They did not have sufficient knowledge about the vitamin $\mathrm{C}$ rich foods that can prevent and cure of vitamin $\mathrm{C}$ related diseases. They only thought that medication is the one and only way to prevent and cure of the diseases. Vitamin C is found in foods and supplements. Fruits and vegetables contain a huge vitamin $\mathrm{C}$ and that is enough for prevention of Vitamin $\mathrm{C}$ related 
diseases $[12,19]$. Deficiency of nutrients including vitamin $\mathrm{A}$, vitamin $\mathrm{C}$, vitamin $\mathrm{E}$ and other several macro and micro nutrients are significantly associated with wound healing. Nutritional support like vitamin $\mathrm{C}$ would benefit both acute and chronic wound healing [20].

Lemon is a rich sources of vitamin $\mathrm{C}$ and can prevent scurvy [21]. We provided 2 lemons (medium size about $150 \mathrm{gm})$ per individuals per day to the lemon supplementation group which contain approximately $80 \mathrm{mg}$ of vitamin C [22]. Doses of vitamin $\mathrm{C}$ means at which Clinical deficiency occurs. Very small doses of vitamin $\mathrm{C}$, no more than 10 $\mathrm{mg}$ /day in adults, are sufficient to prevent scurvy, a condition that is now rare [23]. At moderately low plasma vitamin C concentrations, no derangements in physiology are discernable, save for fatigue at plasma vitamin C concentration below $20 \mu \mathrm{M}$, corresponding to an oral intake of $30-60 \mathrm{mg}$ of vitamin C/day. Antioxidant protection accrues at higher doses is unclear. Current recommended dietary intake for vitamin $\mathrm{C}$ is $90 \mathrm{mg}$ /day for men and 75 $\mathrm{mg} / \mathrm{day}$ for women [23]. At higher doses, this symptom disappears within few weeks [24]. To ensure

the maximum improvement (cure) we provide lemon for four months to lemon supplementation group as a dietary supplement. Interestingly, we found an amazing improvement in this group (Table 2). There are many rich sources of vitamin $\mathrm{C}$ including red pepper, oranges, lemons, indian gooseberries, grape fruits, broccoli, strawberries and tomatoes available in Bangladesh. But other than lemons all are expensive, not available throughout the year and not acceptable to the low income based peoples. Additionally, lemon is very cheap but rich sources of vitamin $C$ that are available throughout the year and lemon juice is not irritating to all classes and all ages of peoples that's why they were easily accepted to consume it in daily basis. People can consume it as juice or through their daily foods and it also a good appetizer. The non-supplementation group also improved their symptoms because of the mix dietary practice but the improvement was very little compared to the lemon supplementation group (Figure 1).

\section{Conclusions}

Vitamin $\mathrm{C}$ is a powerful functional food ingredient with numerous health applications. Proper intake over a lifetime helps to maintain our current health and prevent future ailments. At least $10 \mathrm{mg}$ daily will prevent clinical deficiency. Lemon is a cheap but rich sources of vitamin C which can cure and prevent the vitamin $\mathrm{C}$ related diseases if we consume it regularly. Besides, it has another numerical health benefits. Proper doses of lemon for treatment are extremely variable, and depend upon the disease being treated. The risks of high dose vitamin $\mathrm{C}$ supplementation are almost negligible when compared to some current treatments. In regards to disease management, continued clinical and epidemiological research will help to further understand and confirm the positive health effects from lemon in the prevention and treatment of numerous conditions. In terms of the general public, studies on the long-term effects of overthe-counter oral supplementation of lemon should be focused on, due to increasing awareness of vitamin $\mathrm{C}$ benefits. Future studies should also focus on how to safely and effectively implement lemon as rich sources of vitamin $\mathrm{C}$ into diets of populations at-risk for deficiency.

\section{References}

[1] Li Y, Schellhorn HE. New developments and novel therapeutic perspectives for vitamin C. J Nutr 2007; 137 (10): 2171-84.

[2] Carr AC, Frei B. Toward a new recommended dietary allowance for vitamin $\mathrm{C}$ based on antioxidant and health effects in humans. Am J Clin Nutr 1999; 69 (6): 1086-107.

[3] Balsano C, Alisi A. Antioxidant effects of natural bioactive compounds. Current pharmaceutical design. 2009 Sep 1; 15 (26): 3063-73.

[4] Jacob RA, Sotoudeh G. Vitamin C function and status in chronic disease. Nutr Clin Care 2002; 5: 66-74.

[5] Wang AH, Still C. Old world meets modern: a case report of scurvy. Nutr Clin Pract 2007; 22: 445-8.

[6] Institute of Medicine. Food and Nutrition Board. Dietary Reference Intakes for Vitamin C, Vitamin E, Selenium, and Carotenoids. Washington, DC: National Academy Press, 2000.

[7] Francescone MA, Levitt J. Scurvy masquerading as leukocytoclastic vasculitis: a case report and review of the literature. Cutis 2005; 76: 261-6.

[8] Weinstein M, Babyn P, Zlotkin S. An orange a day keeps the doctor away: scurvy in the year 2000. Pediatrics 2001; 108: E55.

[9] Levine M, Conry-Cantilena C, Wang Y, Welch RW, Washko $\mathrm{PW}$, Dhariwal KR, et al. Vitamin $\mathrm{C}$ pharmacokinetics in healthy volunteers: evidence for a recommended dietary allowance. Proc Natl Acad Sci U S A 1996; 93: 3704-9.

[10] Levine M, Rumsey SC, Daruwala R, Park JB, Wang Y. Criteria and recommendations for vitamin $\mathrm{C}$ intake. JAMA 1999; 281: 1415-23.

[11] Stephen R, Utecht T. Scurvy identified in the emergency department: a case report. J Emerg Med 2001; 21: 235-7.

[12] Njoku PC, Ayuk AA, Okoye CV. Temperature effects on vitamin $\mathrm{C}$ content in citrus fruits. Pakistan Journal of Nutrition 2011; 10 (12): 1168-9.

[13] Ajugwo AO, Erhabor T, Mokogwu T, Digban K, Ojieh G, Nnatuanya I. Nutritional Value of Lime and Lemon in Hypercholesterolaemic Induced Rats. As J Med Sci 2012; 3 (1): 13-6.

[14] Aronson JK. Nature Publishing Group. Retrieved from: http://medicine.nature.com. 2001.

[15] Hirschmann JV, Raugi GJ. Adult scurvy. J Am Acad Dermatol 1999; 41 (6): 895-906; quiz 907-10.

[16] Stallone DD, Brunner EJ, Bingham SA et al. Dietary assessment in Whitehall II. The influence of reporting bias on apparent socioeconomic variation in nutrient intakes. Eur J Clin Nutr 1997; 51: 815-25. 
[17] Shohaimi S, Bingham S, Welch A et al. Occupational social class, educational level and area deprivation independently predict plasma ascorbic acid concentration: a cross-sectional population based study in the Norfolk cohort of the European Prospective Investigation into Cancer (EPIC-Norfolk). Eur J Clin Nutr 2004; 58 (10): 1432-5.

[18] Nelson M, Erens B, Bates B et al. Low Income Diet and Nutrition Survey, Vol. 3. Nutritional Status, Physical Activity, Economic, Social and Other Factors. London: TSO, 2007. http://www.food.gov.uk/multimedia/pdfs/lidnsvol03.pdf

[19] Haytowitz DB: Information from USDA's Nutrient Data Bank. J Nutr 1995; 125: 1952-1955.

[20] Guo SA, DiPietro LA. Factors affecting wound healing. Journal of dental research. 2010; 89 (3): 219-29.
[21] Lind J. A Treatise on the Scurvy. Classics of Medicine Library; 1980.

[22] Mohanapriya M, Ramaswamy L, Rajendran R. Health and medicinal properties of lemon (Citrus limonum). Int $\mathrm{J} \mathrm{A} \mathrm{H}$ Med 2013; 3 (1): 1095-100.

[23] National Research Council. "Food and Nutrition Board. Dietary reference intakes for vitamin C, vitamin E, selenium and carotenoids." (2000): 507-509.

[24] Padayatty SJ, Katz A, Wang Y, Eck P, Kwon O, Lee JH, Chen S, Corpe C, Dutta A, Dutta SK, Levine M. Vitamin C as an antioxidant: evaluation of its role in disease prevention. J Am Coll Nutr 2003; 22 (1): 18-35. 